Culture et histoire dans l'espace roman

$6 \mid 2011$

Figures du pouvoir dans la littérature hispanoaméricaine

\title{
Ronaldo Menéndez : cerdos, caníbales y otras desobediencias
}

Jesús Cano Reyes

\section{OpenEdition}

Journals

Edición electrónica

URL: https://journals.openedition.org/cher/9432

DOI: $10.4000 /$ cher.9432

ISSN: 2803-5992

\section{Editor}

Presses universitaires de Strasbourg

\section{Edición impresa}

Fecha de publicación: 30 junio 2011

Paginación: 257-266

ISBN: 978-2-35410-033-9

ISSN: 1968-035X

\section{Referencia electrónica}

Jesús Cano Reyes, «Ronaldo Menéndez : cerdos, caníbales y otras desobediencias», reCHERches [En línea], 6 | 2011, Publicado el 17 diciembre 2021, consultado el 25 enero 2022. URL: http:// journals.openedition.org/cher/9432 ; DOI: https://doi.org/10.4000/cher.9432

\section{(c) (†) (-)}

Ce(tte) œuvre est mise à disposition selon les termes de la Licence Creative Commons Attribution Pas d'Utilisation Commerciale - Partage dans les Mêmes Conditions 4.0 International. 


\title{
Ronaldo Menéndez: cerdos, caníbales y otras desobediencias
}

\author{
JESÚS CANO REYES \\ Universidad Complutense de Madrid
}

\begin{abstract}
¿Existe ese Menú en lo íntimo de mi alma? ¿Lo he visto cuando esa tarde miré dentro de mí y ya lo he olvidado? Nuestra memoria insular - huelga decirlo - es porosa para el olvido. Yo mismo estoy falseando y perdiendo, bajo la trágica erosión de los años, el justo sabor del huevo y del pan de cada día (Menéndez 2008: 126).
\end{abstract}

Para quien no conozca a Ronaldo Menéndez, estas líneas pueden servir para presentarlo. El que lo haya leído, reconocerá aquí varias de las constantes que reinciden a lo largo de su obra. En primer lugar, el mítico Menú Insular, símbolo obsesivo de la otrora abundante gastronomía de la isla, cornucopia que sobrevive ya tan sólo en un recuerdo que se va debilitando con la lenta acumulación de los días. En segundo lugar, la presencia necesaria de las estrategias (juegos) intertextuales, tanto con los escritores preferidos del autor (en esta cita habrán reconocido el ubicuo aleph borgiano), como también consigo mismo, en un ejercicio de autoplagio cuya última vuelta de tuerca es ofrecer variantes de sus propios textos en Covers, su libro más reciente. Por último, como simbiosis de estos dos, podemos extraer un tercer rasgo distintivo: la conjunción de lo crítico y lo lúdico (dos caminos para rebelarse ante el poder, al fin y al cabo) como dos vasos comunicantes sobre los que Menéndez vierte su obra. Esto no es todo: se incluyen además, tal y como promete el título, cerdos, caníbales y alguna que otra sorpresa no apta para menores. Pero antes hemos de cumplir con el deber de situar al autor en su contexto. 


\section{Dime con quién andas y te diré quién eres}

Ronaldo Menéndez nace en La Habana en 1970. Esto, que a priori no tendría por qué ostentar mayor peso que el de un ingrávido dato biográfico, comporta consecuencias significativas a la luz del cotejo generacional. El profesor Salvador Redonet habla de los "novísimos narradores cubanos", membrete de singular fortuna que se ha consolidado en este caso para referirse a un grupo de escritores nacidos entre 1958 y 1972 y que comienzan a ofrecer sus primeros textos a finales de los ochenta y, sobre todo, comienzos de los noventa. En torno a diversos grupos literarios, como El Establo, Nos-yOtros y Diáspora(s), se va conformando una generación de la que se podría citar a Rolando Sánchez Mejías, Eduardo del Llano, Ena Lucía Portela o Ricardo Arrieta, además del propio Menéndez.

La crítica ha señalado la importancia del momento histórico que viven estos escritores. Hay que pensar, por tanto, que frente a una Mirta Yáñez, que presencia en su juventud los primeros años de la flamante revolución, estos autores son testigos del desencanto que se produce durante la década de los ochenta: las incapacidades del régimen, la guerra de Angola, la invasión estadounidense de Granada o, posteriormente, en el verano de 1994, la «crisis de los balseros», episodio que se repetirá en sus obras. En consecuencia, se producirá en ellos un distanciamiento notable del discurso oficial y de la visión de la Historia que este pretende construir ${ }^{1}$.

Metiendo en un saco los libros de estos narradores, se pueden extraer determinadas características, tanto a nivel temático como estilístico, que configuran su escritura. En cuanto a las primeras, cabe destacar el deterioro de las relaciones humanas, la desconfianza de las instituciones, la sexualidad en su abanico desplegado, el descreimiento en las utopías, la guerra y la violencia. En cuanto a las segundas, sobresalen la fragmentación, el humor, el fantástico o la reflexión metaliteraria (Redonet 1999: 9-23)². Todas

1 A este respecto, Margarita Mateo Palmer comenta lo siguiente: «con el derrumbe del campo socialista, [los Novísimos] presencian la crisis de un discurso y una retórica que habían alimentado largamente una perspectiva ideológica. Hay en ellos una constatación evidente, desde muy temprana edad, de la diferencia entre la historia real -aquella que viven cotidianamente- y la oficial -la que se divulga a través de la prensa y los medios masivos de comunicación -» (Mateo Palmer 2002: 53).

2 Además de los trabajos de Salvador Redonet, para ahondar en la comprensión de la generación de los "novísimos" y estudiar sus características más destacadas, recomiendo consultar Martín Sevillano 2001; Rodríguez Coronal 2009: 221-235; Rubio Cuevas 2001 : 547-554. 
ellas, en mayor o menor medida, se pueden aplicar a la obra de Ronaldo Menéndez ${ }^{3}$.

Uno de estos "novísimos" rasgos que Margarita Mateo Palmer destaca, junto a la sexualidad y al espejismo, es el de la intertextualidad. En las obras de Menéndez, como se anunció antes, aparecen todos los tipos de transtextualidad imaginables, no sólo en un ámbito estrictamente literario (Borges, Vallejo, Cortázar, Valéry o Calvino son sólo algunos de los innumerables embajadores convocados por su palabra y protagonistas de guiños, citas, plagios y referencias de toda índole), sino también en un diálogo fluido con otras artes como el cine o la pintura ${ }^{4}$. No obstante, el palimpsesto genettiano no se detiene aquí: las obras de los Novísimos introducen con picardía referencias a los propios autores de la generación, creando de este modo una malla de espeso tejido que encierra en sí misma a sus propios artesanos.

En este momento, cabe plantearse la pregunta de cuál es la posición de los Novísimos dentro del campo literario cubano. Iván Rubio advierte un problema al destacar la «doble insularidad» (vale decir doble aislamiento) de sus autores, refiriéndose tanto al mercado internacional como al nacional (Rubio Cuevas 2001: 547-554)5. Si el primero aparece copado por otras figuras de mayor renombre y ventas, como Zoé Valdés, el segundo ha tratado de exaltar la posición social marginal desde la que escribe el grupo para minimizar su visión iconoclasta. Sin embargo, esta operación por parte de las estructuras de poder no esconde lo que en realidad es un mero artificio de los narradores, quienes simulan abandonar el salón intelectual apropiándose de voces provenientes de las esferas a las que quieren

3 Esta se compone hasta la fecha de tres libros de cuentos (El derecho a pataleo de los ahorcados, 1997; De modo que esto es la muerte, 2002; Covers. En soledad y compañía, 2010) y tres novelas (La piel de Inesa, 1999; Las bestias, 2006; Río Quibú, 2008), además del libro, también de cuentos, escrito en la adolescencia y a cuatro manos con Ricardo Arrieta (Alguien se va lamiendo todo, 1997), ganador del Premio David 1990 y víctima de la censura en la isla.

4 Martín Sevillano, en su tesis doctoral, analiza en profundidad el potente vínculo existente entre las artes plásticas y la literatura, entre las que hay una «unidad de acción y de estilo [...] que en el ámbito de un arte social es de extrema importancia pues los agentes de ambos campos actúan [...] en virtud de un mismo habitus» (Martín Sevillano 2001: 83).

5 Rodríguez Coronel incide en la existencia de una doble vertiente que divide artificialmente la literatura cubana: "Así, se ha promovido una bifurcación que remite a la existencia de dos literaturas cubanas en pugna: una dentro del país y otra en el extranjero, una comprometida con la Revolución y otra en contra del proyecto revolucionario» (Rodríguez Coronel 2009: 233). 
representar. Tal y como afirma el propio Menéndez, «se articula un autor letrado que escamotea su situs en la estructura de las tomas de posición dentro del campo intelectual, para sumergirse en un discurso participativo de esta subalternidad» (Menéndez 2000: 220). Precisamente sobre esto vamos a hablar ahora.

\section{Voces en la orilla}

Desde sus orígenes, el género del testimonio surge como una manifestación de la alteridad discursiva que se opone a la voz oficial impuesta desde el centro. No obstante, los avatares del testimonio en Cuba (también en Nicaragua) marcan un camino particular cuando a partir de 1970 el poder trata de llevarlo a su terreno y así neutralizar sus amenazas; para ello, el Premio Casa de las Américas crea la categoría del testimonio, desactivando de este modo el potencial peligro que el discurso disidente pudiera causar.

Como contraposición a este movimiento, los Novísimos buscan la desautomatización de un género que corre el riesgo de la inocuidad paciendo despreocupadamente dentro de los recintos del poder. De este modo, sus textos recurren a voces periféricas que incomodan y aguijonean la pretensión institucional de una lectura unánime sobre la realidad del país. El propio Menéndez prefiere hablar de un componente testimonial o un "Cuento-testimonio », ya que el género primitivo ha sido usurpado y es, por tanto, inservible:

El peso de la ortodoxia del testimonio, tal como ha sido institucionalizado en nuestro país, es aligerado y desplazado, hacia la condición de componente testimonial en la obra de la más reciente promoción de narradores cubanos. Dicha desautomatización del género se resuelve subvirtiendo algunos ejes del discurso: el ideológico, el referencial, el formal y el argumental; y manteniendo otros como indicadores de una redefinición (Menéndez 2000: $222)^{6}$.

Los dos ejemplos más evidentes de esta reelaboración del testimonio en la producción de Ronaldo Menéndez aparecen en su obra breve. En el cuento "Las palmeras detrás», incluido en El derecho a pataleo de los ahorcados, se cede la palabra a los protagonistas del éxodo: los balseros que abandonan la isla cuando en 1994 el régimen abre las puertas del mar. Así, los tres fugitivos (Juan, Yoni y el Indio), narradores alternados del relato, se lanzan al agua en una historia cuyas premoniciones desde el comienzo prefiguran el trágico

6 Además de Menéndez, también Martín Sevillano ha analizado el tratamiento del testimonio por parte de los Novísimos (Martín Sevillano 2002: 298-302). 
final. El lenguaje, entonces, como corresponde al género, refleja (registra) el modo de hablar de sus personajes: "Coño, Indio; qué clase de trastazo te diste. ¿Cómo fue eso, socio? Eso por estar en la bobería, ahora figúrate tú. Apenas empezamos y ya estás jodido" (Menéndez 1999: 100). Frente a la "isla del diablo", el destino soñado aparece como un espacio casi mítico engrandecido por la imaginación: "Dicen que allá eso está lleno de luces y con los edificios que se meten en el cielo y tienen nieve en el techo. ¿No debieran verse las luces ya?» (108). Finalmente, cuando todo está perdido, tan sólo la religión puede crear para ellos una ilusión de salvación.

La misma técnica de alternancia de voces levanta el relato "Carne», en De modo que esto es la muerte. En él son Bill y Cirilo Ojo Tuerto los que llevan a cabo el robo de una vaca ante los aprietos del hambre y la escasez de proteínas. El haz de luz se desplaza en esta ocasión a la falta de comida, que ataca de manera democrática; poco importa que sus protagonistas sean traductores, críticos o magíster para que se vean abocados a cometer un latrocinio necesario. La crítica, la defensa de la palabra silenciada, se enlaza, como siempre, al humor; así, Cirilo comenta :

No comprendo eso de hacerse vegetariano, y menos por designio superior. A fin de cuentas uno se parece más a un tigre que a un oso panda. Coma carne: millones de felinos, la tigridad misma, no puede estar equivocada. Aquí no hay siquiera bosques de bambú (Menéndez 2002: 13).

Tampoco esta vez la historia culmina con un final feliz, aunque sí sorprendente: muerta la vaca, Bill y Cirilo son descubiertos y detenidos por los granjeros, quienes pretenden denunciar el delito pero no a los delincuentes: las autoridades retirarán la vaca muerta, pero ellos constituirán el plato de comida de los granjeros: «no es nada personal, en este lugar todos vivimos de esto. Una vaca muerta, que no pudo ser robada, es una sábana de filetes sobre nuestras mesas» (19). Sin lugar a dudas, el tema del hambre se impone como una de las grandes desobediencias del escritor cubano, pero este desmesurado apetito se manifiesta de muy diferentes maneras, como veremos a continuación.

\section{El cerdo kafkiano o todo por la carne}

El cerdo es un animal que goza de una amplia tradición en el mundo de las letras. La Biblia lo considera un animal impuro e inmundo y prohíbe incluso tocar su cadáver. El antropólogo Marvin Harris, quien trata este tema, habla de las culturas donde, en lugar del repudio, impera la pasión 
porcina: «El amor a los cerdos es otra cosa. Es un estado de comunidad total entre el hombre y el cerdo [...] La gente sólo puede ser realmente humana en compañía de ellos» (Harris 1993: 47). Dentro de la literatura, por citar sólo un ejemplo, podemos pensar en el totalitario cerdo orwelliano de Animal Farm.

El cerdo de Menéndez es «una máquina de devorar todo lo que no sea su propio cuerpo ». Tras diferentes papeles secundarios (nada desdeñables), alcanza el rol protagónico en Las bestias, donde Claudio, el triste profesor de instituto, alimenta, al igual que el resto de sus vecinos, un cerdo en su bañera con el evidente fin de terminar comiéndoselo. Esta situación kafkiana, que se produce en la Cuba real y obliga a una prohibición por parte del Estado, es característica del espacio que Menéndez dibuja en sus obras, donde generalmente no se nombra a Cuba, pero se alude a ella de manera inevitable ${ }^{7}$. Inevitable es también pensar en la isla al leer las últimas palabras de Claudio: "Engordaré mucho antes de acostarme por última vez. Mi cuerpo va a ser como un caimán dormido» (Menéndez 2006: 122).

El texto de esta novela surge de la intersección de dos cuentos anteriores: "Cerdos y hombres», de De modo que esto es la muerte, y "Castigo y crimen", de El derecho a pataleo de los ahorcados. La novela desemboca en un brillante triángulo alimenticio del que participan uno de los sicarios, Claudio y el cerdo famélico. Si para Marvin Harris, como hemos recordado, la comunión con el cerdo permite al hombre alcanzar la categoría completamente humana, Menéndez prefiere la inversión especular para conseguir que su cerdo transfiera la condición de bestia al resto de personajes que lo rodean, animalizando al ser humano. De este modo se pone de manifiesto otra de las características de los Novísimos que enumerábamos al principio: el deterioro o la cosificación de las relaciones humanas. Esto le permite indagar en asuntos tan espinosos como el del racismo proveniente, no de las clases de menor nivel cultural, sino de la intelectualidad.

La vaciedad del estómago se manifiesta a lo largo de toda su obra. Los cuatro primeros cuentos de De modo que esto es la muerte aparecen agrupados bajo el membrete de «Hambre». Allí, además de los textos ya comentados,

7 No obstante, cabe señalar que a raíz de la ya remota partida del escritor, la imagen de la Cuba real se va desdibujando en su memoria y en su construcción mental hasta adquirir un tinte onírico e irreal. Como él mismo afirma en una entrevista concedida al programa de radio "Hora América», de RNE, el 22 de abril de 2010, "para mí Cuba ha dejado de ser un espacio de vivencias cotidianas para convertirse en un espacio simbólico, en una reminiscencia, en una metáfora. Yo lo que tengo de Cuba es una materia prima bastante distorsionada ya por mi memoria». 
se relata la «pesca de altura »; esto es, la destreza de los vecinos para pescar gatos en los tejados de las casas ataviados de una caña y un anzuelo. En Río Quibú, la falta de comida se materializa en la añoranza del Menú Insular, nostalgia que planea por todo el libro; así, Yoni el Rubio afirma lo siguiente a su hijastro Júnior: "Esto es una isla estrangulada y con la lengua afuera, aquí no hay futuro ni cuando se muera el General, la gente se ha echado a perder por culpa de la extinción del Menú Insular» (Menéndez 2008: 67-8). Los ejemplos son innumerables. A día de hoy, el relato "Menú Insular", publicado en Covers, parece cerrar la temática del hambre al recopilar en un solo relato todas las historias de animales comestibles reiteradas una y otra vez en los cuentos y novelas, donde el cerdo, el avestruz, el cocodrilo o el gato sufren el apetito del hombre.

Sin embargo, no es solamente la proteína animal la que enriquece la dieta de la isla. En efecto, el canibalismo es otra de las prácticas habituales en el universo de Ronaldo, la cual se expresa a través de la voracidad de la antropofagia intertextual de su autor, pero también por medio de la antropofagia más instintiva de sus personajes. Ya hemos hablado del relato "Carne», donde aparecen los granjeros caníbales. En "Cerdos y hombres ", el negro enjaulado, más allá del borde de la inanición, comienza a comerse al protagonista. En Las bestias, que desarrolla esta historia germinal, el canibalismo se presenta de un modo más implícito, pero no se le oculta al lector que Claudio (la bestia humana) devora al cerdo (la bestia animal) que ha devorado al negro.

Ya en Río Quibú el canibalismo se convierte en un tema central. Júnior, en la búsqueda del asesino de su madre, descubre que los habitantes de los márgenes del río se alimentan de carne humana. Ante la escasez, también el cuerpo del homo sapiens se convierte en alimento ${ }^{8}$, animalizándose una vez más su figura, ahora reducida a cazador y presa. El hombre se iguala entonces al cerdo: «Esa gente es una máquina de devorar todo lo que no sea su propio cuerpo, sobre todo si es un cuerpo bípedo, implume y rubio» $(139)^{9}$.

Al mismo tiempo, la ingestión del hombre por el hombre representa la venganza, como en el caso de Júnior: «Pero yo extrañaba la carne de verdad.

8 Aunque con otra significación, destaca la escena de canibalismo divino que aparece en «El bucle de Villa Búho», donde los discípulos se comen a Jesús.

9 Ya en "Cerdos y hombres", al igual que en Las bestias, se había adelantado esta nivelación: «Era increíble cómo los cerdos se parecían a las personas» (Menéndez 2002: 35); «sus ojos, según verifico, se parecen a los del puerco» (Menéndez 2006: 101). 
La oscura carne, esa que era el pan de cada día en los márgenes del Quibú. Así fue como de golpe [...] decidí matar y comerme al culpable más inmediato de mi situación de prófugo" (108). El cuerpo es víctima de una violencia inusitada, perdiendo casi todo vestigio de vida. Así sucede en la violación que el protagonista ejerce sobre la muchacha del Quibú (de la misma manera se violenta el simpático microcuento de Monterroso): "Cuando Júnior despertó, el amasijo de carne violada seguía estando allí» (91).

Una forma particular de canibalismo y de la violencia sobre el cuerpo está presente en el relato «La ciudad de abajo», de Covers, donde en los subsuelos de París se oculta una secta que considera que la automutilación es el regalo necesario del amor y sus miembros han de entregar a sus amados una parte física y tangible de ellos mismos. Esto empieza ya a confundirse con la doble significación del cuerpo en la literatura de Menéndez. Como bien afirma Eduardo Becerra, «el cuerpo es al mismo tiempo actor y escenario de sus tramas; en dos vertientes muy claras: el canibalismo, por un lado, y el sexo, por otro» (Becerra 2008: 167). Una vez detallado el asunto de la lucha antropófaga, resta hablar de la otra batalla más amable, en principio, de los cuerpos.

\section{La profundidad de la piel}

No cabe duda de que las diferentes manifestaciones del sexo que relatan los libros de Menéndez pretenden escapar de la imposición de los rígidos esquemas y suponen una nueva rebelión contra el modelo establecido. En "Últimas discusiones conyugales", perteneciente a De modo que esto es la muerte, una mujer, para vengar la infidelidad del marido y ante la imposibilidad de prostituirse, decide tener sexo con un perro. Los cuentos de Covers desarrollan una amplia gama de posibilidades sexuales, en la que hay tríos y hay también orgías, como sucede en "Ejército desnudo». En mitad del campo, un grupo de actores desnudos representa las cuatro estaciones por medio del deseo y de sus cuerpos. Los habitantes de los alrededores, al contemplar el espectáculo, se van adhiriendo a una orgía que crece descontroladamente y que favorece relaciones de todo tipo entre sus integrantes: «de más está decirle que muchos de mis actores, sin importar la sempiterna correspondencia que vincula un sexo a su complemento, hacían el amor sobre la hierba fresca del mediodía» (Menéndez 2010: 68). Las autoridades, claro, acabarán deteniendo el espectáculo. 
Río Quibú presenta una sexualidad desatada en el personaje de Julia, quien muy temprano empieza a ensayar la interacción de su cuerpo con todo su entorno: «Esa misma noche supo que había agotado el reino elemental de la masturbación cuando logró copular con la punta de un rayo de luna que se colaba entre los visillos» (Menéndez 2008: 35). Al mismo tiempo, su hijo Júnior evidencia un constante complejo de Edipo hacia la madre muerta: "Cuando Júnior la viola por segunda vez lo hace con los ojos cerrados e imagina a su madre» (80). Iluminando estos territorios oscuros, Ronaldo Menéndez muestra caminos sexuales que escapan a la normalidad con el fin de ampliar un concepto para él demasiado restringido ${ }^{10}$.

Sin embargo, el caso más paradigmático es la novela La piel de Inesa, bildungsroman que relata el tránsito a la madurez de un niño de doce años a través del descubrimiento del sexo con Inesa, una mujer adulta que lo seduce (probablemente un mismo modelo más contenido a partir del cual se modelará después a la Julia de Río Quibú). El erotismo y la sensualidad de la obra se construyen por medio de un lenguaje extraordinariamente barroco y poético:

No lograba entender que las manos de una mujer que podía ser su madre quisieran tratarlo de ese modo, con mañas de hembra, llamando las cosas por su nombre. Inesa trató de explicarle más de una vez que aquello seguía siendo tan natural como el agua sobre el cuerpo, que se trataba del deseo, del lenguaje de la piel y de la carne, que había que dejar que los cuerpos hablaran en su idioma como se les dejaba beber un vaso de agua cuando tenían sed, para ella no había ninguna diferencia (Menéndez 1999: 167).

El gran simbolismo que teje el libro se puede ejemplificar en la lectura de cómo la sexualidad aparece siempre relacionada con la lluvia en el patio, lluvia que golpea a los amantes y que adquiere para el niño la fuerza de un bautismo que nunca recibió en su infancia. Al conocerse la historia, el trágico final desemboca en la muerte de Inesa ahorcada por el pueblo enfurecido, si bien el lector no siente tentaciones de juzgarla de un modo tan severo.

Y hasta aquí, por hoy, la degustación de desobediencias. Hemos asistido a la reformulación genérica del testimonio, la denuncia del hambre o el ensanchamiento del cauce conceptual del sexo, aunque son muchas más las

10 En una entrevista publicada en La Gaceta de Cuba, Menéndez afirma: «Me obsesiona el cuerpo, ese entrañable desconocido. Sigo creyendo firmemente, con Paul Valéry, que lo más profundo es la piel. No imagino la Libertad sin la absoluta libertad del juego de los cuerpos» (Redruello 2007). 
búsquedas literarias que Ronaldo Menéndez desarrolla para subvertir las formas de poder. Otro día, por supuesto, podemos hablar de más.

\section{Bibliografía}

Becerra, Eduardo, 2008, «Cuba Caníbal», Cuadernos hispanoamericanos, Madrid, nº 697-698, julio-agosto 2008, p. 166-168.

Harris, Marvin, 1993, Vacas, cerdos, guerras y brujas. Los enigmas de la cultura, Madrid, Alianza.

Martín Sevillano, Ana Belén, 2001, Cuento cubano actual (1985-2000), Tesis Doctoral, Madrid, Universidad Complutense de Madrid.

Martín Sevillano, Ana Belén, 2002, «Algunos aspectos del cuento de los Novísimos narradores cubanos», Anales de Literatura Hispanoamericana, Madrid, no 31, 2002, p. 295-312.

Mateo Palmer, Margarita, 2002, «La narrativa cubana contemporánea: las puertas del siglo XXI», Anales de Literatura Hispanoamericana, Madrid, no 31, 2002, p. 51-64.

Menéndez, Ronaldo, 1997, El derecho a pataleo de los ahorcados, Madrid, Lengua de Trapo.

Menéndez, Ronaldo, 1999, La piel de Inesa, Madrid, Lengua de Trapo.

Menéndez, Ronaldo, 2000, «El gallo de Diógenes. Reflexiones en torno a lo testimonial en los novísimos narradores cubanos», Encuentro de la Cultura Cubana, Madrid, $\mathrm{n}^{\circ}$ 18, otoño 2000, p. 215-222.

Menéndez, Ronaldo, 2002, De modo que esto es la muerte, Madrid, Lengua de Trapo.

Menéndez, Ronaldo, 2006, Las bestias, Madrid, Lengua de Trapo.

Menéndez, Ronaldo, 2008, Río Quibú, Madrid, Lengua de Trapo.

Menéndez, Ronaldo, 2010, Covers. En soledad y compañía, Madrid, Páginas de Espuma.

Redonet, Salvador, 1999, Para el siglo que viene: (Post)novísimos narradores cubanos, Zaragoza, Prensas Universitarias de Zaragoza.

Redruello, Laura, 2007, «Tras la pista de los Novísimos. Una conversación con el escritor Ronaldo Menéndez», La Gaceta de Cuba, La Habana, n 2007.3.

Rodríguez Coronel, Rogelio, 2009, «Avatares de la narrativa cubana más reciente» in Jesús Montoya Juárez y Ángel Esteban (ss dir.), Miradas oblicuas en la narrativa latinoamericana contemporánea, Madrid, Iberoamericana, p. 221-235.

Rubio Cuevas, Iván, 2001, "La doble insularidad de los novísimos narradores cubanos", in Carmen Alemany Bay et al. (ss dir.), La Isla Posible, Alicante, Universidad de Alicante, p. 547-554. 